\title{
EXPERIMENTAL STUDY OF HEAT TRANSFER AND FLOW CHARACTERISTICS OF LIQUID FALLING FILM ON A HORIZONTAL FLUTED TUBE
}

\author{
A. M. I. Mohamed \\ Mechanical Power Department, Faculty of Engineering, \\ Suez Canal University, Port-Fouaad, Port-Said, Egypt. \\ e-mail :mohamed.av@gmail.com Tel. : +20101597112
}

\begin{abstract}
The aim of the present study is to investigate experimentally the effect of the fluted surface tube on the heat transfer and flow characteristics of liquid falling film. Experiments have been indicated that, when a liquid falling film falls on a horizontal fluted surface tube, the transition starts at low Reynolds number than that of the plain tube. The value of the film thickness has been slightly decreased by decreasing the fluted pitch. A reduction of the film thickness was observed at about $9 \%$ for the low fluted pitch tube, at Reynold's number of 485 . A clear reduction of the dimensionless wavelength, $\lambda^{*}$, has been occurred at low fluted pitch tube. The use of enhanced surfaces can provide heat coefficients higher than those obtained from plain tube. Heat transfer enhancement was noticed due to the use of fluted tube surface. An improvement of the Nusselt number reached about $45 \%$ for low fluted pitch tube. However, the low values of the fluted pitch increased the heat transfer enhancement that of the high values.
\end{abstract}

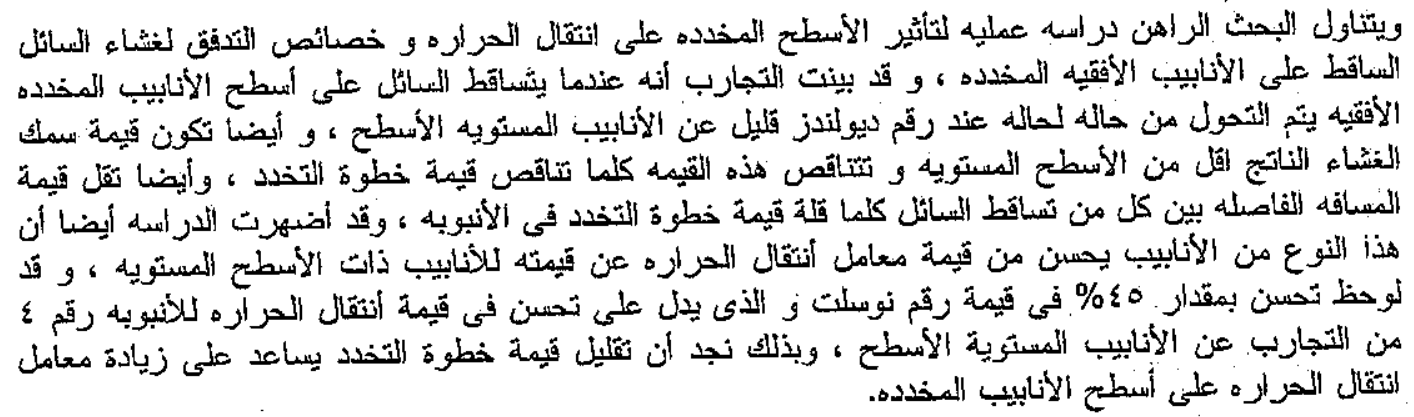

Keywords: falling film, horizontal tube, fluid flow, heat transfer enhancement, heat exchangers.

\section{INTRODUCTION}

Heat Exchangers using falling film on the outside surface of horizontal tube plays an important role in many industries, such as : desalination and fresh water treatment industry, chemical and petrochemical industries, refrigeration, and food, and dairy industries. Heat exchangers employing this process have advantages over the more conventional heat exchangers. These advantages are the pressure drop of the liquid flowing over the tubes is negligible, the quantity of cooling liquid required is small, and the heat transfer coefficients are high [1]. They also offer advantages in dealing with liquid distribution, noncondensable gases, fouling and many other operating problems of the heat exchangers.

When a falling liquid film falls from a horizontal tube to another horizontal tube below it, basically three different patterns of flow between the tubes can be observed: discrete droplets, liquid column (or jet), and continuous liquid sheet, as shown in Fig. 1. Each of these flow patterns depends on the flow rate, the tube spacing, and the physical properties of the liquid [2]. Each pattern of flow affects in the heat transfer through the tube.

During the last few years many researcher have performed many studies on flow behavior and the heat transfer of film flow falling on the surface of horizontal tube. However, modeling the mechanism of the flow pattern and the heat transfer over a horizontal falling film tube needs more details. Mitrovic [2] studied experimentally the heat transfer and the mechanism of the flow from a horizontal heated tube to a falling subcooled liquid film. The experimental results obtained by Mitrovic [2] indicated that the flow pattern depends not only on the film Reynolds number, Re, but also on the tube spacing. The study showed also that the transition from droplet mode to the jet mode occurred at Reynolds numbers between 150 and 200 , while transition from the jet mode to the sheet mode 
occurred at Reynolds between 315 and 600 for water as a working medium.

Additional experimental observations were given by $\mathrm{Hu}$ and Jacobi [3] for the flow characteristics and mode transitions of the falling film on horizontal tube, and new flow classifications were provided. A simplified flow regime map for the falling film mode transitions was developed. The experimental study was conducted by using several working media to achieve a wide range of Reynolds number, Re, and Galileo number, Ga. The second part of the study concerns with the mode effects on sensible heat transferred to a falling liquid film [4].

The review study of Ribastski and Jacobi [5] covered the available literature about horizontal type falling film type evaporators, focusing on the technical difficulties of the process. The study also covered the flow pattern studies and the experimental parameters that affect the heat transfer performance on plain single tube, enhanced surfaces and tube bundles. In addition, a comprehensive review of the significant efforts to develop mathematical models and empirical correlations to explain the flow pattern, and heat transfer coefficient was presented. [6] used an integral method for the solution of the equations of motion and energy for laminar falling film flow on horizontal tube. A non-dimensional equation was expressed for the laminar film thickness at any position as function of Reynolds number, Re, Archimedes number, $\mathrm{Ar}$, and the angular position on the horizontal tube. Later, Rogers and Goindi [7] measured experimentally the film thickness of water falling on a large diameter horizontal tube. The measured thickness of laminar falling films was compared to the theoretical values, and a new predicted correlation of the film thickness was developed. Eq. (1).

$$
\left.\frac{\delta}{d}\right)_{\min }=1.186 \mathrm{Re}^{1 / 3} A r^{-1 / 3}
$$

A theoretical analysis was presented by Kocamustafaogullari and Chen [8] to simulate the hydrodynamics and heat transfer of the liquid falling on a tube bundle of horizontal tube evaporator. Liquid falling from one tube to the lower one is considered as a thin liquid jet impinging on the top of the tube with uniform free falling velocity. The solution of the hydrodynamic and thermal equations was obtained by a finite difference method. Liquid film thickness and local average heat transfer coefficients were obtained for the case of constant heat flux and isothermal boundary conditions.

The distance between two neighboring droplets or jets, in droplet and jet modes only, falling from the tube has a fixed value, as shown in Fig. 1. This distance is defined as the wavelength, $\square$, of the falling film. In addition to the mode of the film and the film thickness, the wavelength is considered to be an important parameter to understand the falling film flow behavior. The wavelength can be calculated according to equations given by Lienhard and Wong [9] :

$$
\begin{aligned}
& \lambda_{c}=2 \pi \sqrt{\left(\frac{g \Delta \rho}{\sigma}+\frac{2}{d^{2}}\right)^{-1}} \\
& \lambda_{d}=\lambda_{c} \sqrt{3}
\end{aligned}
$$

The experimental measurements, by Mitrovic [2], found that the value of the wavelength, $\square$, lies between the critical and the dangerous values. The effect of the tube diameters, tube spacing, and liquid flow rates on the film wavelength. were experimentally investigated using four working fluid by $\mathrm{Hu}$ and Jacobi [10]. They concluded that the wavelength depends on flow rate and decreases for an increase in Reynolds number. A weak dependence on tube diameter was observed, with wavelength increasing with tube diameter. The dependence on tube spacing was also observed to be the weakest. Finally, the wavelength had been successfully correlated to $\mathrm{Re}, \mathrm{Ga}^{1 / 4}$ and tube diameter, and a new more widely applicable correlation was provided. Yung et al. [11] developed an equation to estimate the wavelength of low viscosity liquids, like water, ethyl alcohol and ammonia. On the other hand for high viscosity liquids, Taghavi and Dhir [12] reported that wavelength is larger than that for low viscosity liquids. Droegemueller [13] studied experimentally the flow behavior of the falling film of very high viscous fluid, like Glycerin or mixture of water and Glycurin.

Enhanced tubes are widely used in horizontal falling film heat exchanger to improve the heat transfer. Falling film on an enhanced tube was studied by many workers. Roques and Thome $[14,15]$ presented the flow mode transitions for four types of enhanced tubes, Wieland Gewa-K40 (40 fpi), Wieland GewaK19 (19 fpi), and Wolverine low fin tube (26 fpi \& 29 fpi). A comparison between these tubes and the plain tube were made to see the effect of fins and fins density on the transitions. The main findings were that the high fin density ( 40 fpi) did not affect the transition very much compared to the plain tube transitions, while the lower fin densities (29 and 26 fpi) tend to increase the transition Reynolds number.

An experimental study was carried out, by Liu and Yi [16], for the evaporation heat transfer of water and R-11 falling film across horizontal smooth tube and two kinds of structured tube. The experimental results showed that the structured tube can greatly enhance the falling film evaporation heat transfer either for water or for R-11. Liu and Yi found that the increase in the heat transfer coefficient in the 
falling film due to the surface tension effects and an increase in the surface area.

Recently, Mohamed [17] found that, when a liquid falling film falls on a horizontal rotating tube, the transition starts at low Reynolds number. To avoid instable falling film during rotation of the tube, the tube speed of rotation should not exceed the maximum speed of rotation.

The enhanced or structured surfaces tube can be used to increase the heat transfer coefficients on the horizontal falling film. Chyu and Bergles [18], found that the heat transfer enhancement provided by the structured surface is a consequence of the increase in the surface area.

The temperatures of the fall fluid at the upper part of the test tube (inlet) and the lower part of the test tube (exit), and the surface temperature of the tube are measured by using K-Type

The previous investigations highlighted that the horizontal falling film behavior needs more details and extensive investigations to clear the flow behavior and the quantity of the heat transfer through the process. On the other hand, studying the effect of the fluted surface tube on the flow behavior and the heat transfer is very important for the different applications and heat transfer enhancement in this type of flow.

\section{EXPERIMENTAL SETUP}

To run the experiments, an experimental test rig had been designed for testing the flow behavior and to measure the quantity of the total heat transfer through the tube. A schematic diagram of the experimental test rig is shown in Fig. 2. The test rig mainly consists of the collecting tank, the circulating pump, the distribution header, the upper dummy tube, the test tube, the lower dummy tube, inlet steam feeder and exit steam tube. The fluid flows through a closed circuit, the fluid in the tank is circulated by a small pump to the rest of the circuit. The quantity of the fluid flow is controlled by a by-pass system via control valves. The fluid is then passed through a Rotameter, with an accuracy of $1 \%$, to measure the volume flow rate of the fluid. Then, the fluid flows via a vertical tube into the distribution header from three upper inlets.

Saturated steam at 1 bar exit supplied from the boiler is used to heat the inside surface of the test tube. The steam enters and exhausts from the tube at saturated conditions. This means that the inner surface of the tube is kept at constant temperature.

The fluid leaves the distribution header at the bottom through $1 \mathrm{~mm}$ diameter holes spaced $2 \mathrm{~mm}$ apart over a length of $400 \mathrm{~mm}$. The fluid then falls from the distribution header over the upper dummy tube. Consequently, the fluid falls freely from the upper dummy tube to the test tube, which has a diameter of $19 \mathrm{~mm}(3 / 4 \mathrm{inch})$ and a length of $450 \mathrm{~mm}$. Tubes spacing, between dummy and test. tubes, are considered fixed at $40 \mathrm{~mm}$.

The temperatures of the fall fluid at the upper part of the test tube (inlet) and the lower part of the test tube (exit), and the surface temperature of the tube are measured by using K-Type thermocouples. The thermocouples are about $0.5 \mathrm{~mm}$ diameter and about $0.1{ }^{\circ} \mathrm{C}$ accuracy of reading. Figure 3 , illistrates the location of the temperature measurements over the test tube.

Four fluids are used as test fluids. These fluids are water, mixture of $50 \%$ glycol and $50 \%$ water, glycol, and oil. These fluids cover a wide range of Galileo number, as presented in table (1). Digital Camera, Canon (Power Shot, S10, 2.1 Mega Pixels), is used to capture the falling film images through the experiments in the digital form.

\section{EXPERIMENTAL PROCEDURE}

Two groups of tests were conducted with the test facility, the first group is for testing the flow behavior without heating. While the second group of experiments are conducted under heating of the test tube to measure the heat transfer through the falling process. Both groups are executed for different test fluids (water, mixture of $50 \%$ ethylene glycol and $50 \%$ water, ethylene glycol, and oil), different flow rates ( $\mathrm{Re}$ between 0.4 and 507 ) but at constant wall temperature. All measurements were made under steady state and isothermal ambient temperature conditions for the first group. While the test rig was insulated for the second group experiments. The test fluid was firstly circulated througl the test rig for one hour to reach the steady state conditions.

During the flow behavior experiments (first group), digital images were recorded for each run at certain conditions. Two images were captured at two different positions, one for the longitudinal direction and the other for the cross section direction, as shown in Fig. 1. The image from the longitudinal direction was used to estimate the value of the wavelength, पुWhile the image of the cross section of the tube was used to estimate the film thickness, ज़

The digital camera was adjusted to capture the images at high resolution $(1200 \times 1600$ dpi) XGA mode. These high resolution digital images were analyzed using PhotoShop (ver. 7) software to measure each of the film thickness and the wavelength. The number of pixels, of the film thickness or the wavelength, were measured from the image and compared with the number of pixels of the scale to calculate the dimensional value of the film thickness or the wavelength in ( $\mathrm{mm}$ ). 
For mode transition experiments, the flow was increased slowly to obtain the different modes of flow by adjusting the control valve. The transition from one mode to another was observed visually, and the flow rate for each transition was recorded.

To measure the quantity of heat transfer from the heating steam to the falling fluid, thermocouples are use to measure each of the fluid and wall temperature. This leads to calculate the heat transfer coefficient between the falling film and the test tube for different geometries of the test tube and fluid flow rates.

\section{RESULTS AND DISCUSSION}

A series of experiments were carried out for the case of plain and different geometries fluted surface tube to measure the film thickness and the wavelength of the falling film. In addition, the evaluation of the mode transitions were observed for both the case of stationary and rotating tubes. Moreover, the effect of fluted surface geometry on the heat transfer coefficient between the falling fluid and the tube are studied.

One plain tube and three different geometries fluted (enhanced) tubes are used in the experiments. The plain tube is used as a reference to evaluate the fluted effect of the tube surface on both of the fiuid and heat transfer behavior. Figure 4 shows the main geometry for each of the plain and fluted surface tubes. While the details of the geometry of each tube are listed in table 2 . Figure 5 is a photograph for the tube number 3.

The experimental results showed only a small degree of hysteresis for increasing or decreasing the fluid flow rate. Therefore the effect of the hysetersis could be neglected. As there are five modes of flow and by neglecting the effect of the hysteresis, there are four falling film mode transitions. The flow regime map for the falling film mode transitions is a relation between Galileo number, $\mathrm{Ga}$, and Reynolds number, Re. For the present study, the flow regime map was constructed to explain the effect of the geometry of the fluted tubes on the mode transitions.

\subsection{Falling Film Flow Modes for Stationary Tubes}

For plain tube the falling film flow modes transitions were experimentally observed. In order to construct the flow regime for the plain tube case and the present tube geometry, correlations between Reynolds number, $\mathrm{Re}$, and Galileo number, $\mathrm{Ga}$, for transitions were predicted in a power form.

$$
\left(\mathrm{Re}=\mathrm{a} \mathrm{Ga}{ }^{\mathrm{b}}\right)
$$

The transition correlations are based on the experimental data. Table 3 presents the constants of the correlations for each transition, also the RMS deviation percent of the data. The maximum RMS deviation is about $8 \%$. The flow regime map for stationary tube is shown in Fig. 6. Using the designed map, the flow mode could be estimated from the Galileo number, $\mathrm{Ga}$, and Reynolds number, Re, of the flow. Estimating the flow mode is very important, because the flow mode plays an impcrtant role in the calculations of the heat transfer coefficient and the design of the horizontal falling film heat exchangers.

\subsection{Effect of Geometry of Fluted tube on the Falling Film Mode Transitions}

The effect of the geometry of the fluted tube, mainly the pitch, on the mode transition of the falling film has been studied experimentally for the three fluted and plain tubes as depicted by table 2 . Figures $7-a$ and 7-b show a transition from the droplet mode to droplet-jet mode and droplet - jet to jet mode for different fluted and plain tubes. For these modes of flow the transition is slightly affected by the type of tube, however a small effect has been observed at high values of $\mathrm{Ga}$.

Figures. 7-c, and 7.d, show the same effect as in Figs. 7-a, and 7-b but for the others two modes of transitions, jet / jet-sheet, and jet-sheet / sheet. For both modes of operation the transition starts at low Reynold's number, when the fluted pitch of the test tube decreases specially at high values of $\mathrm{Ga}$. The decrease of the pitch of the fluted tube causes an increase of the surface roughness of the tube and reduces the value of the surface tension. The reduction of the surface tension force leads to increases the falling fluid from the tube.

The effect of the fluted pitch on the mode transition for the case of droplet mode, or at low Reynolds number, is lower than in the case of jet mode. Table 3 presents the constants of the correlations for each transition at different speeds of rotation of the tube.

\subsection{Effect of Geometry of Fluted tube on the Film Thickness}

Film thickness was experimentally measured for the stationary tube in a wide range of Reynolds numbers, e.g. different mass flow rates, and different working fluids. Then the measured values were compared with the predicted values from Eq. 1 as shown in Fig. 8 . The measured value showed good agreement with that predicted from the Eq. 1, as shown in Fig. 8. The comparison shows that the maximum deviation between the measured and the predicted values was about $11.6 \%$. However, this value is absolutely acceptable due to the difficulty of the measurements and the accuracy of the predicted value.

Figure 9 presents the value of the film thickness for the plain and fluted tubes. As shown in the figure, the value of the film thickness is small value compare to that of the plain tube film thickness. The lower value of the film thickness appears when the pitch of the 
fluted tube has a lower value (Tube 4). About 9\% reduction of the film thickness was observed at Reynolds number of 485 and tube number 4.

\subsection{Effect of Geometry of Fluted tube on the Wavelength}

The wavelength of the falling film is considered as one of the most important fluid characteristics in the falling film flow behavior. The dimensionless wavelength, $\lambda^{*}$, is defined as the falling film wavelength, or the spacing between two neighboring jets or droplets, divided by the capillary constant, as follows;

$$
\lambda^{*}=\frac{\lambda}{\xi}, \text { where } \xi=\sqrt{\frac{\sigma}{g \rho}}
$$

In Fig. 10 the dimensionless wavelength, $\lambda^{*}$, is plotted against Reynolds number for different fluted and plain tubes. The experimental data clearly show that, the wavelength of the falling film depends mainly on the Reynolds number and the fluid properties. This was also reported by $\mathrm{Hu}$ and Jacobi [9]. Generally, Fig. 10 shows that there is a confirmation of the reduction of the wavelength due to the decrease of the pitch of the fluted tube, especially for oil or high viscosity fluids. The results for using ethylene glycol as a test fluid indicate that the effect of the pitch of the fluted tube on the wavelength is smaller than for oil. While, weak effect on the wavelength appears for water and $50 \%$ ethylene glycol and $50 \%$ water mixture as a low viscosity test fluid.

The small value of the pitch of the fluted tubes causes a reduction in the surface tension. This causes also a reduction in the value of the adhesions force between the fluid and the tube surface and increasing the volume of the fluid falling down to the next tube. The increase of the volume flow rate of the fluid from the tube to the next down tube causes a decrease in the space between the jets or droplets and the wavelength.

\subsection{Effect of Geometry of Fluted Tube on the Heat Transfer Enhancement}

The heat transfer has been experimentally tested for the plain horizontal tube for a wide range of Reynolds numbers, e.g. different mass flow rates, and different working fluids. Then the measured values were compared with the predicted ones from Eq. 6 as shown in Fig. 11. The measured value showed good agreement with that predicted from the Eq. 6 [7]. The comparison shows that the maximum deviation between the measured values and the predicted values was about $16 \%$. However, this value is absolutely acceptable due to the difficulty of the measurements and the accuracy of the predicted value from the equation.

$$
N u=1.734 \mathrm{Re}^{-1 / 3} A r^{1 / 3}
$$

Falling film heat transfer coefficients on both horizontal plain and fluted tubes have been experimentally tested in order to evaluate the improvement of the heat transfer coefficient. The heat transfer enhancement is defined as the ratio between the Nusselt number for fluted tube, $\mathrm{Nu}_{\mathrm{f}}$, to the plain tube Nusselt number, $\mathrm{Nu}_{\mathrm{p}}$, which is $\left(\mathrm{Nu}_{\mathrm{f}} / \mathrm{Nu}_{\mathrm{p}}\right)$. It is clear from Fig. 12 that the geometry of the fluted tube plays an important role in the heat transfer enhancement. For tube 2 when the pitch of fluted surface has a high value, the enhancement of the heat transfer has a low value. While, the enhancement has higher values for tube 3 for fluted pitch at $3 \mathrm{~mm}$.

The highest value of $\left(\mathrm{Nu}_{\mathrm{f}} \mathrm{Nu}_{\mathrm{p}}\right)$ appears with tube number 4 when the pitch is $3 \mathrm{~mm}$. However, the improvement of the Nusselt number reaches about $45 \%$. While the lower enhancement factor is for tube number 2 , which has a pitch of $7 \mathrm{~mm}$. It means that the decrease of the fluted pitch increases the heat transfer enhancement for the horizontal falling film tubes.

It is believed that the enhancement in the heat transfer for the fluted tube is due to many parameters, like that, the distortion of the velocity and temperature fields, the transition and the mode of the flow behavior. The presence of the repeated roughness elements causes in fact a disruption of the boundary layer and induces a secondary flow, which both enhance the convective heat transfer.

\section{CONCLUSIONS}

An experimental analysis has been presented for the effect of the fluted surface tube on the heat transfer and flow characteristics of liquid falling film on a horizontal tube. Three different geometries of the fluted tube are compared with the plain tube to evaluate this effect. The study showed that, the mode transition starts early (at lower Reynolds number) using the fluted tube, as well as increasing the pitch of the fluted tube yield to earlier mode transitions.

The film thickness of the flow decreased by increasing the fluted pitch. The observed reduction was about $9 \%$ of the film thickness at Reynolds number of 485 and tube number 4 , which has a smaller pitch. A clear reduction of the dimensionless wavelength, $\lambda^{*}$, occurred due to the fluted surface, especially at low value of the fluted pitch.

Enhancement of the heat transfer was noticed due to the use of fluted tube surface. An improvement of the Nusselt number reached about $45 \%$ for smaller tube pitch. However, the low values of the fluted pitch increased the heat transfer enhancement than that of the high values. 


\section{REFERENCES}

[1] Adams, F.W., and Conn; A.L., "A horizontal film type cooler - Film coefficients of heat transmission", Industrial Engineering Chem., 28 (1936), pp. 537.

[2] Mitrovic, J., "Influence of tube spacing and flow rate on heat transfer from a horizontal tube to a falling liquid film", International Heat Transfer Conference, San Francisco, Vol. 4. (1986), pp. 1949-1956.

[3] Hu, X., and Jacobi, A.M., "The intertube falling film: Part 1 - Flow characteristics, mode transitions, and hysteresis", Transactions of the ASME, Vol. 118 (August 1996), pp. 616-625.

[4] Hu, X., and Jacobi, A.M., "The intertube falling film: Part 2 - Mode effects on sensible heat tramsfer to a falling film", Transactions of the ASME, Vol. 118 (August 1996), pp. 626-633.

[5] Ribastski, G., and Jacobi, A.M., "Falling - film evaporation on horizontal tubes - a critical review, International Journal of Refrigeration", Vol. 28 (5) (August 2005), pp. 635-653.

[6] Rogers, J.T., "Laminar falling film flow and heat transfer characteristics on horizontal tubes", Canadian Journal of Chemical Engineering, 59 (1981), pp. 213-222.

[7] Rogers, J.T., and Goindi, S.S., "Experimental laminar falling film heat transfer coefficient on a large diamter horizontal tube", The Candian Journal of chemical Engineering, 67 August (1989), pp. 560-568.

[8] Kocamustafaogullari, G., and Chen, I.Y., "Falling film heat transfer analysis on a bank of horizontal tube evaporator", AIChe Journal, Vol. 34 (9) (September 1988), pp. $1539-1548$.

[9] Lienhard, J.H., and Wong, P.T.Y., "The dominant useable wavelength and minimum heat flux during film boiling on a horizontal cylinder", Transaction ASME journal of heat transfer, Vol. 86 (1964), pp. 220-226.

[10] $\mathrm{Hu}, \mathrm{X}$., and Jacobi, A.M., "Departure-site spacing for liquid droplets and jets falling between horizontal circular tubes", Experimental Thermal and Fluid Science, 16 (1998), pp. 322331.

[11] Yung, D., Lorentz, J.J., and Ganic, E.N., "Vapor/liquid interface and entrainment in falling film evaporators", Journal of Heat Transfer, 102 (1980), pp. 20-25.

[12] Taghavi, K., and Dhir, V.K., "Taylor instability in boiling, melting and condensation or evaporation", International Journal of Heat and Mass Transfer, 23 (1980), pp. 1433-1445.

[13] Droegemueller, P., "Viskose Rieselfilme im Waagerechten
Stroemungsformen", Waermeuebertragung und Mechanische Beeinflussung, VDI-Verlag, Reihe 19 (Nr. 113) (1998), Duesseldorf.

[14] J. F. Roques, J. R. Thome, "Falling film transitions between droplets, column and sheet flow modes on a vertical array of horizontal 19 fpi and 40 fpi low finned tubes", HEAFT 2002, Kruger Park South Africa, (8-10 April 2002), pp. 523-528.

[15] Roques, J.F., and Thome, J.R., "Falling film transitions between droplets, column and sheet flow modes on a vertical array of horizontal 19 fpi and 40 fpi low finned tubes", Heat Transfer Engineering, 24 (6) (2003), pp. 40-45.

[16] Liu, Z.H., and Yi, J., "Enhlanced evaporation heat transfer of water and R-11 falling film with the roll-worked enhanced tube bundle", Experimental Thermal Fluid Science, 25 (6) (2001), pp. 447 - 455.

[17] Mohamed, A.M.I., "Flow behavior of liquid falling film on a horizontal totating tube", Experimental Thermal and Fluid Science, 31 (2007), pp. 325-332.

[18] Chyu, M.C., and Bergles, A.E., "Horizontal tube falling film evaporation" with structured surfaces", Journal of Heat Transfer, Vol.'111 (1989), pp. 518-524.

\section{NOMENCLATURE}

Ar Archimedes number

D tube diameter, $m$

Dpi dot per inch

$\mathrm{Ga}$ Galileo number

Re film Reynolds number

$\mathrm{Nu}$ Nusselt number

$\mathrm{S}$ space between tubes, $\mathrm{m}$

\section{Greek}

$\delta \quad$ film thickness, $m$

I total liquid mass flow rate of the film per unite length of the tube, $\mathrm{kg} / \mathrm{m} \mathrm{s}$

$\lambda$ space between two jets or droplets, wavelength, $\mathrm{m}$

$\lambda^{*}$ dimensionless wavelength $=\lambda / \xi$

$\mu$ dynamic viscosity of the film, $\mathrm{kg} / \mathrm{m} \mathrm{s}$

$\rho$ density, $\mathrm{kg} / \mathrm{m}^{3}$

$\sigma \quad$ surface tension, $\mathrm{kg} / \mathrm{s}^{2}$

$\xi \quad$ capillary constant $=\sqrt{\sigma /(g \rho)}, \mathrm{m}$

\section{Superscript}

* dimensionless

\section{Subscript}

F . Fluted surface tube

P Plain tube

min minimum 


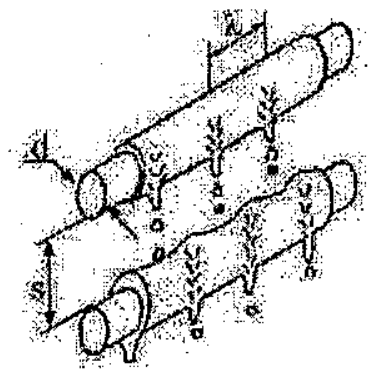

(4)

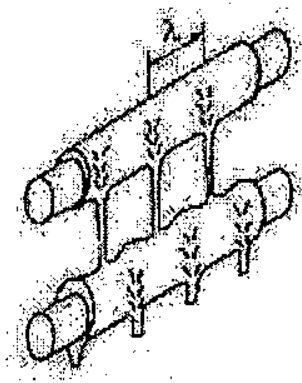

(b)

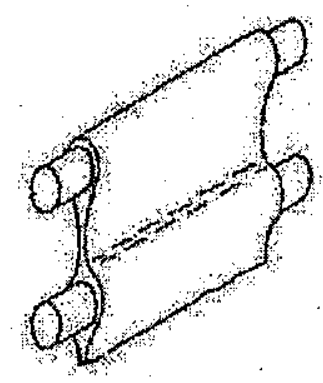

(c)

Fig. 1 Patterns of liquid flow between two horizontal tubes:

(a) droplets, (b) jet, (c) sheet

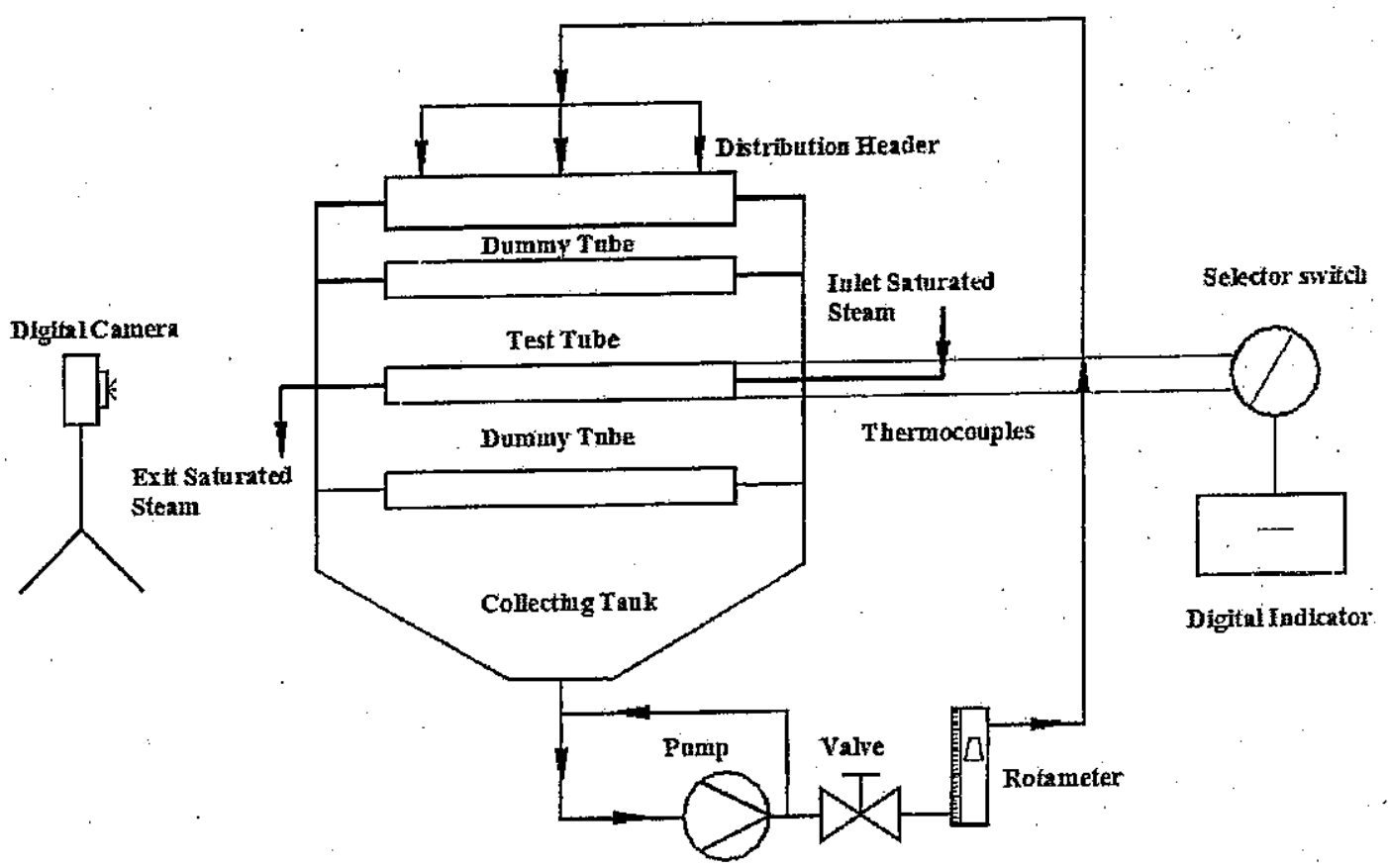

Fig. 2 Schematic diagram of the test rig.

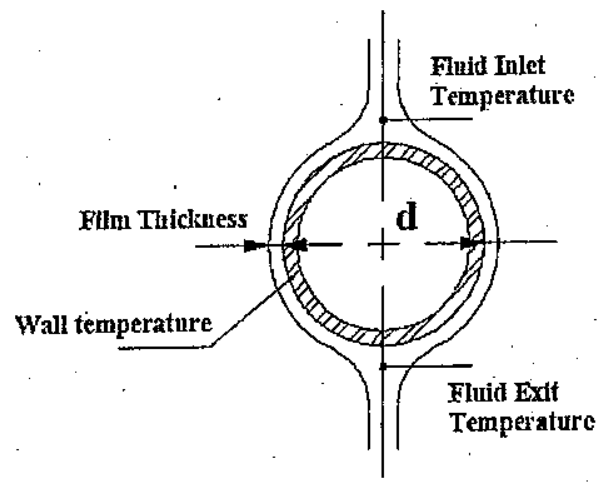

Test Tube

Fig. 3 Film thickness and temperature measurements locations. 


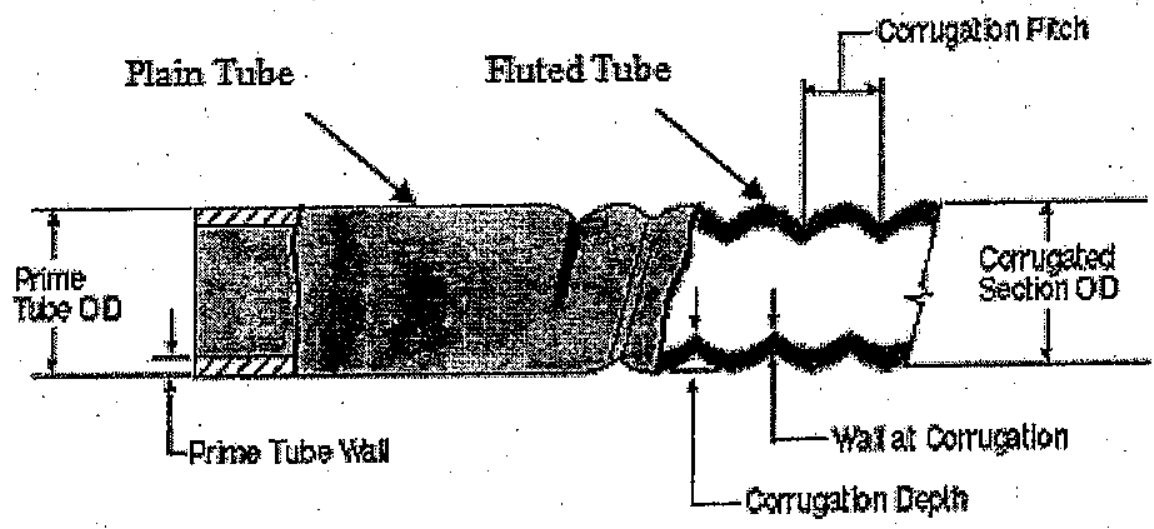

Fig. 4 Geometry of plain and fluted tube.

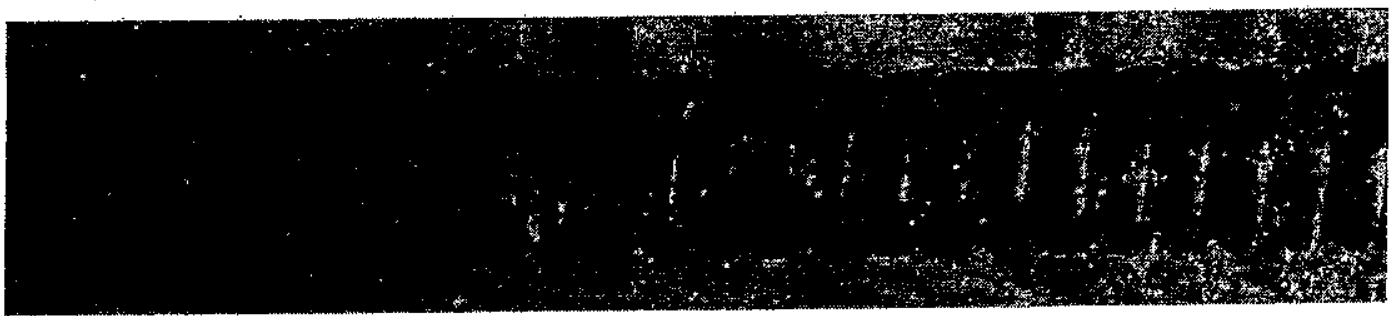

Fig. 5 Fluted tube No. 3.

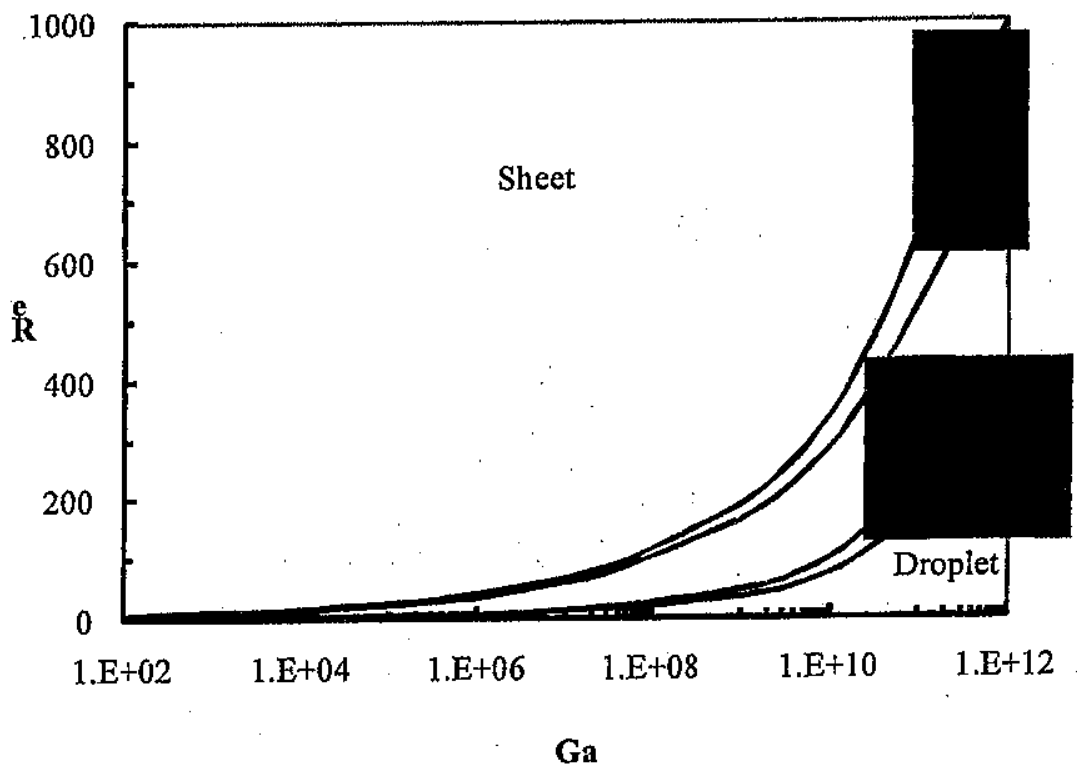

Fig. 6 Flow regime map for stationary tube 


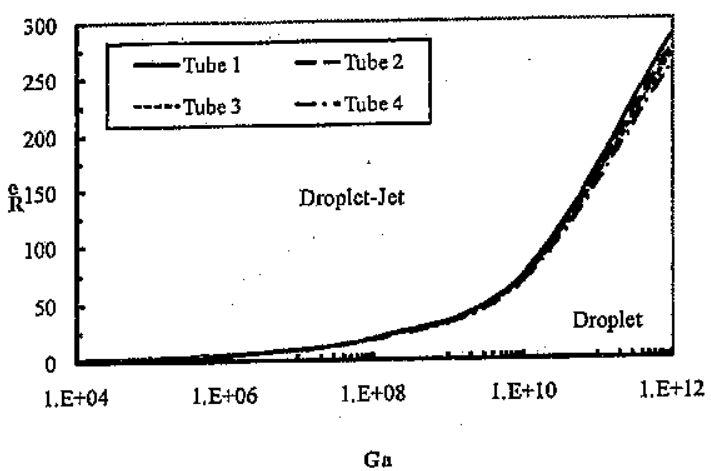

(a)

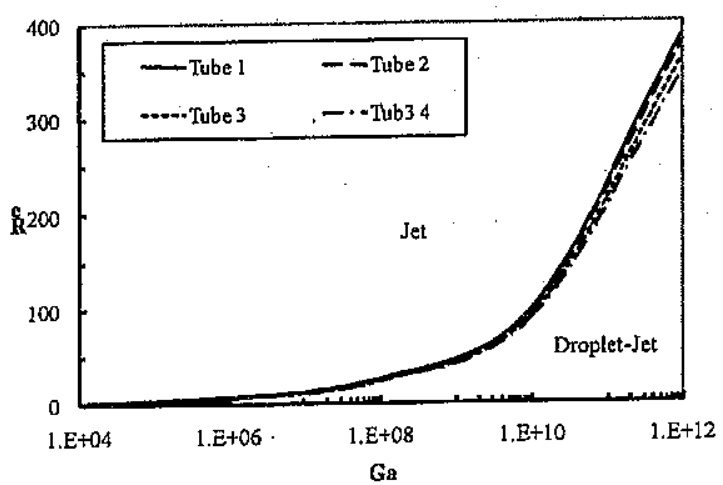

(b)

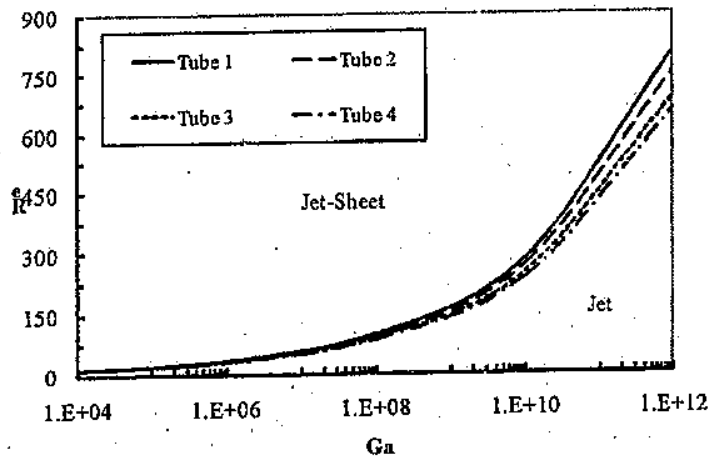

(c)

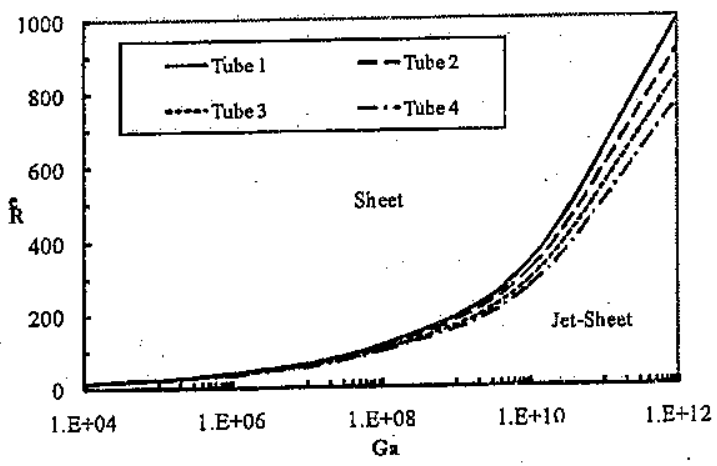

(d)

Fig. 7 Mode transitions for different tube geometry.

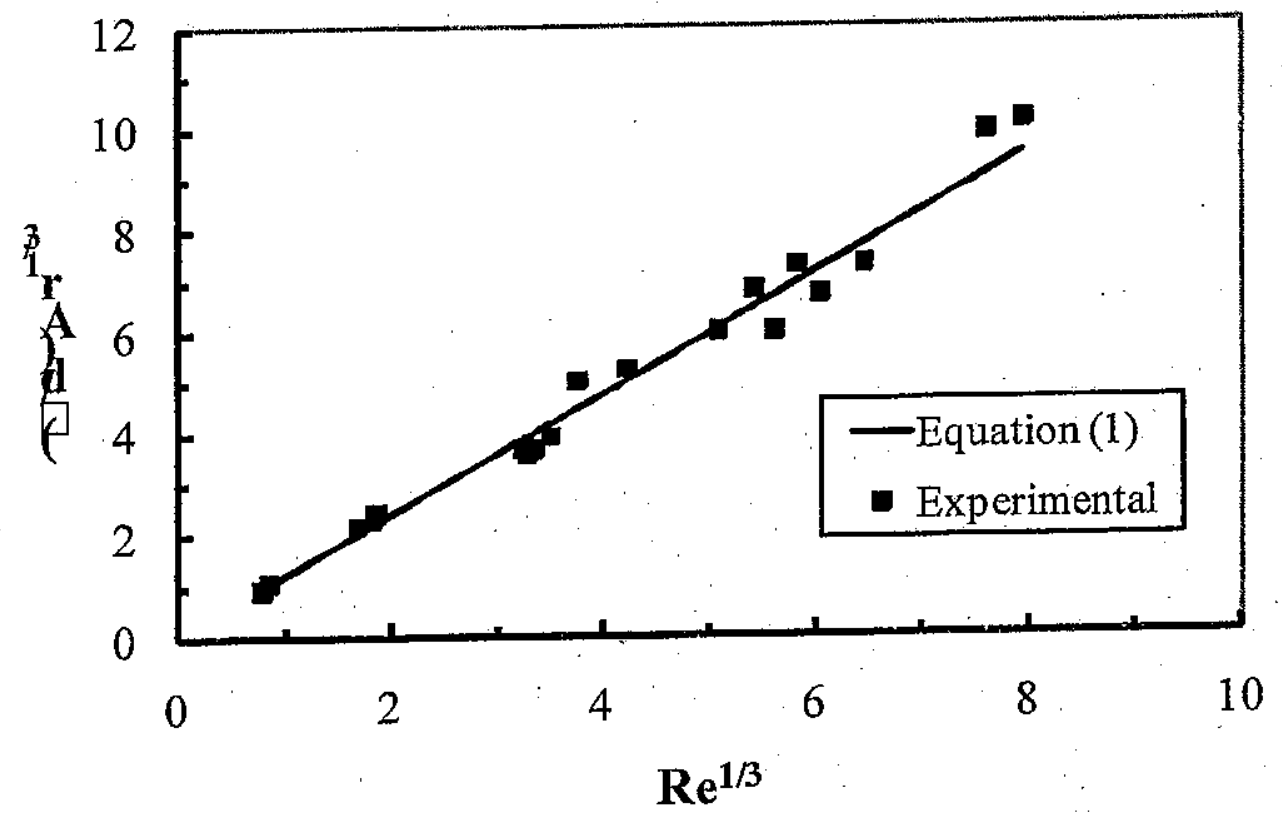

Fig. 8 Comparison of measured film thickness values with predicted values from Eq. (1), [7]. 


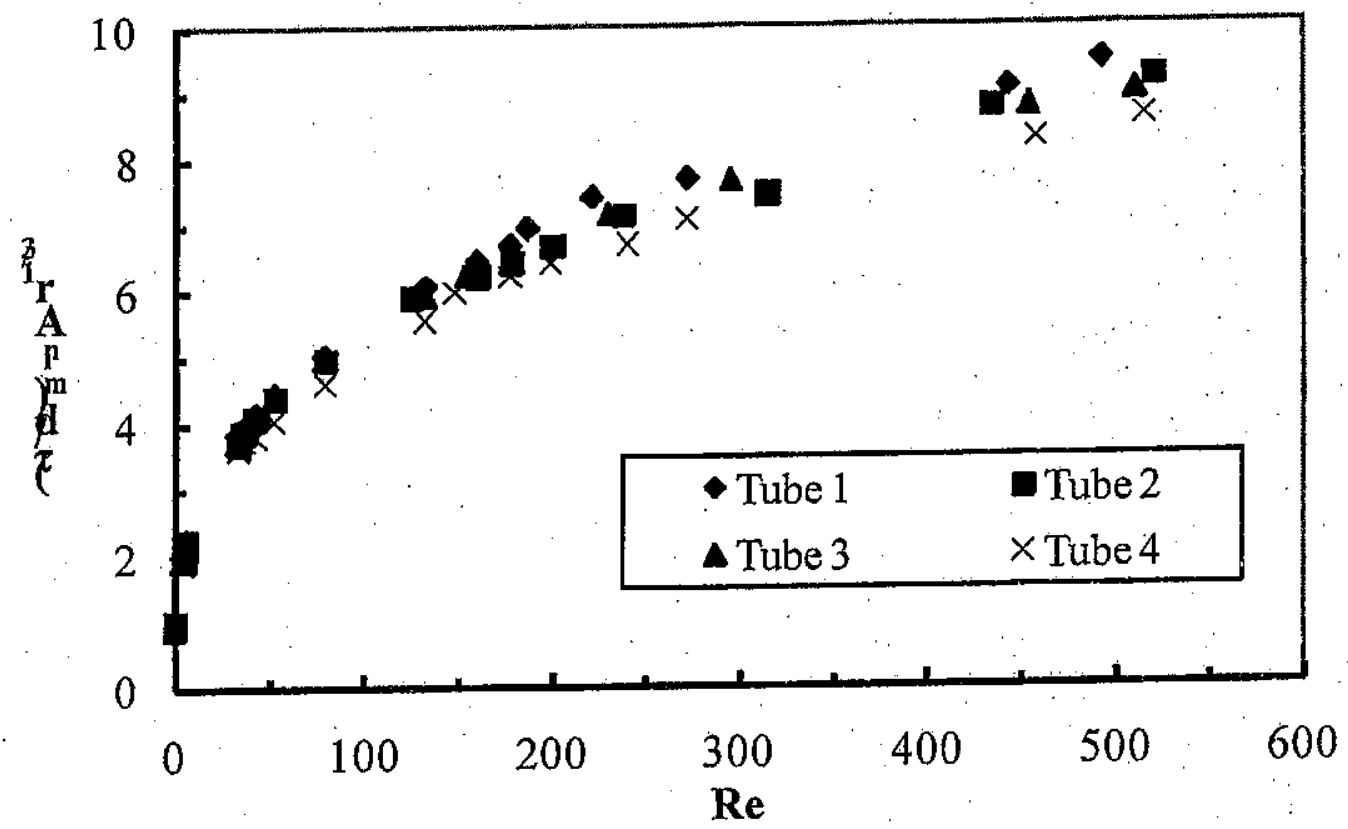

Fig. 9. Effect of fluted tube geometry on the film thickness.
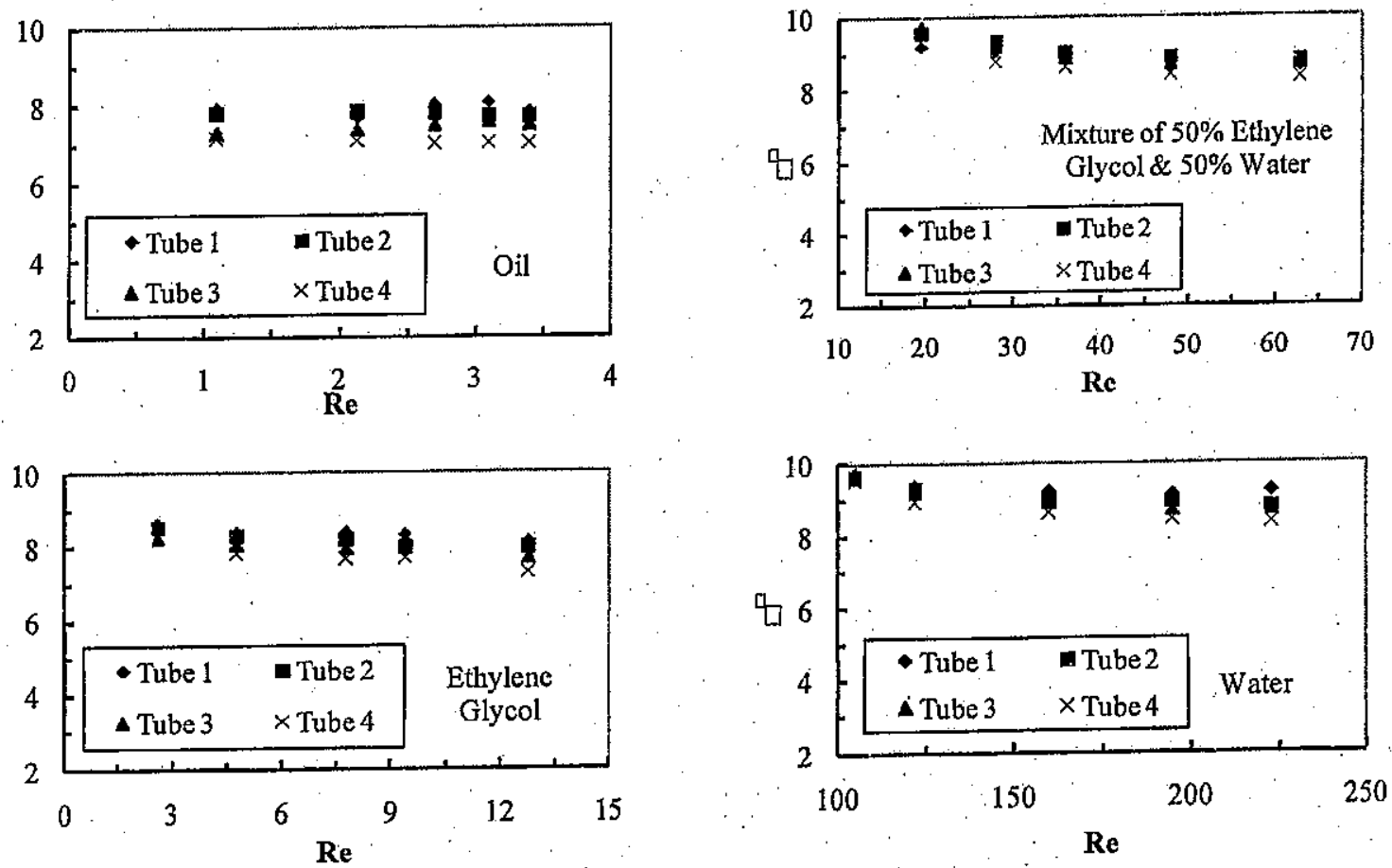

Fig. 10 Effect of fluted tube geometry on the falling film wavelength. 
A. M. I. Mohamed, "Experimental Study of Heat Transfer and Flow Characteristics of Liquid Falling Film ..."

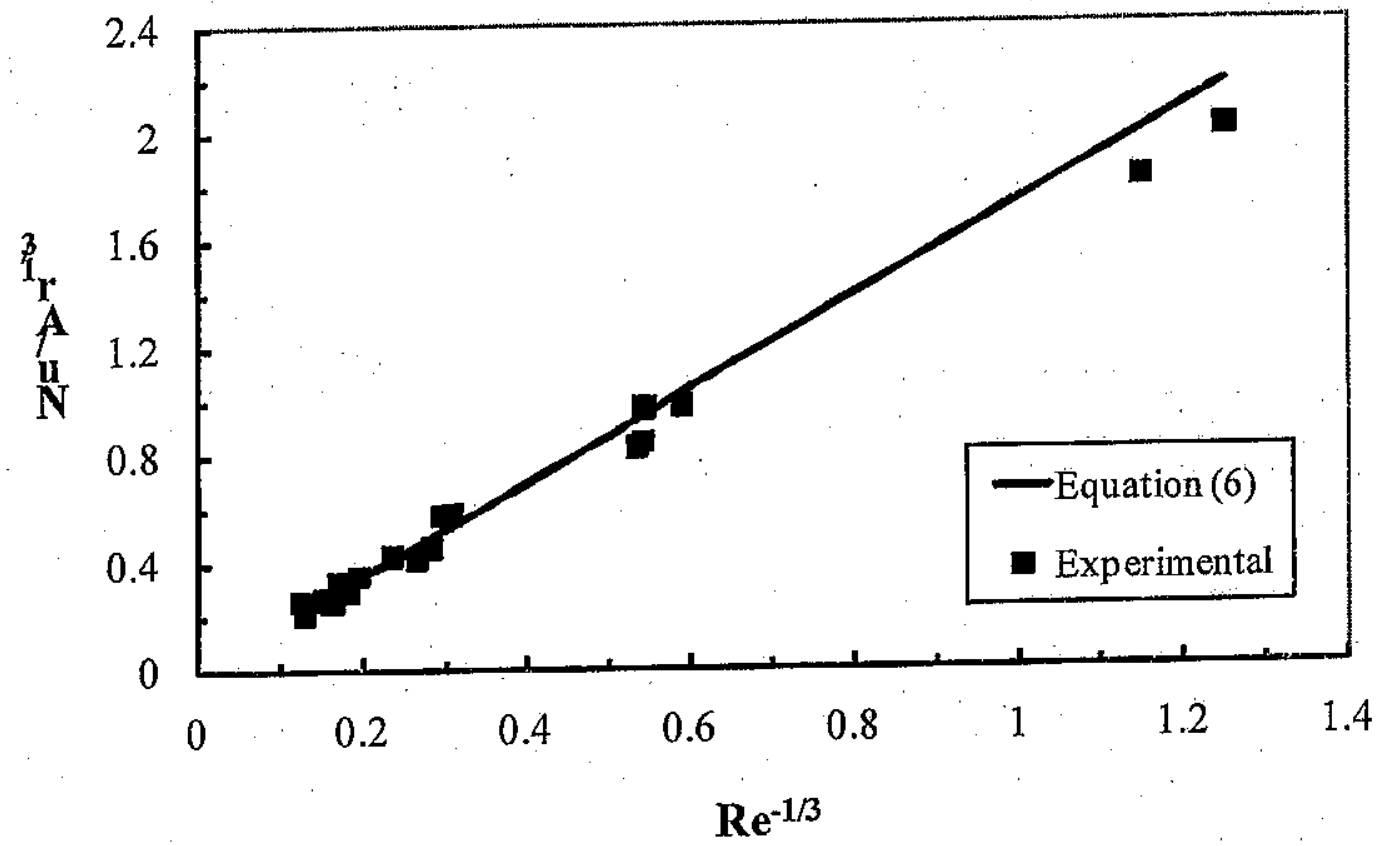

Fig 11 Comparison of measured values of heat transfer coefficient with predicted values from Eq. (6), [7].

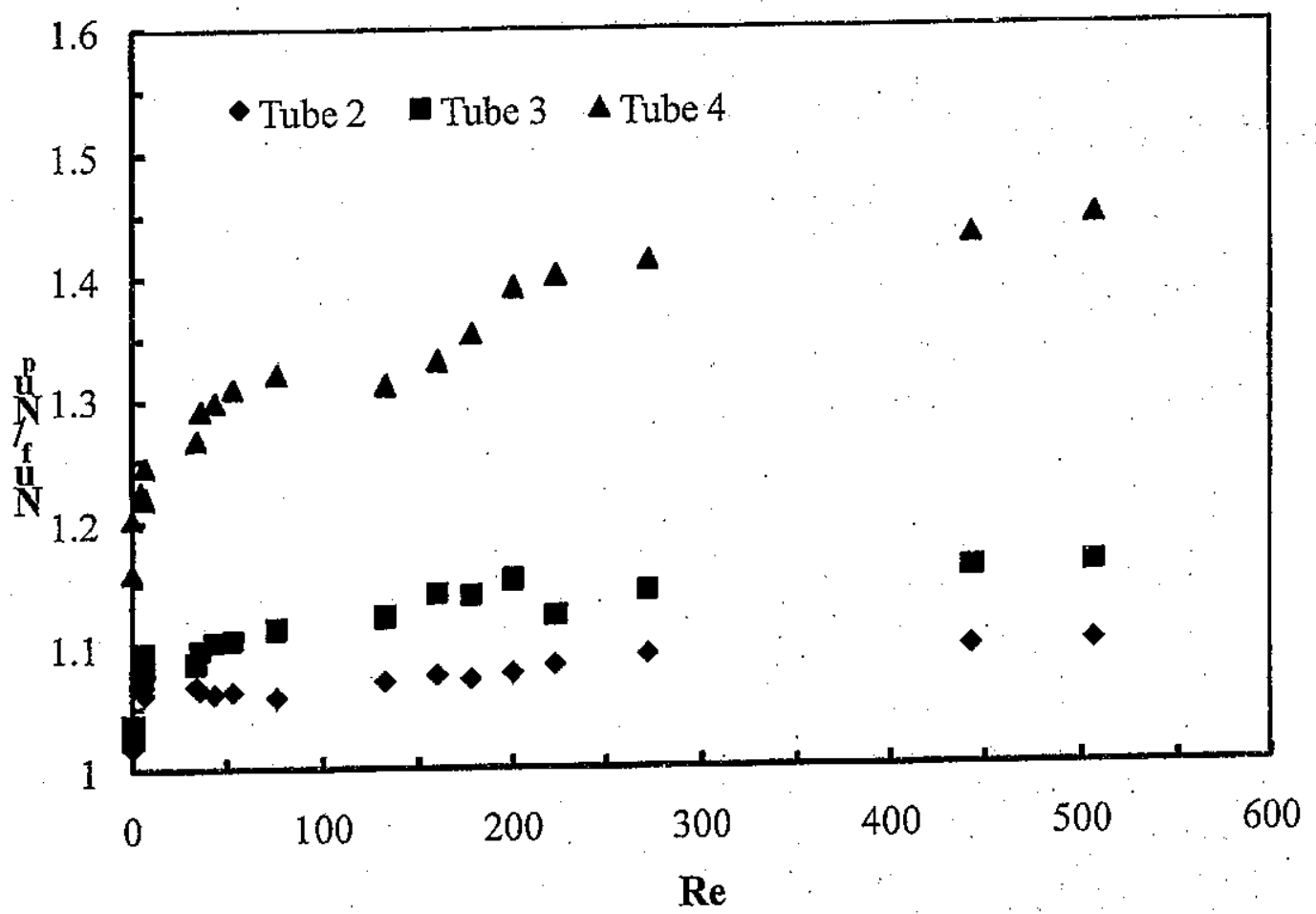

Fig. 12 Effect of fluted tube geometry on the falling film heat transfer coefficient. 
Table 1 Test Fluids

\begin{tabular}{|l|c|c|c|c|}
\hline Test Fluid & Water & $\begin{array}{c}50 \% \text { E. Glycol \& 50\% } \\
\text { water mixture }\end{array}$ & E. Glycol & Oil \\
\hline $\begin{array}{l}\text { Galileo number, } \\
\text { Ga }\end{array}$ & $8.91 \times 10^{10}$ & $6.55 \times 10^{8}$ & $104.86 \times 10^{4}$ & 600.4 \\
\hline
\end{tabular}

Table 2 Test tube geometry.

\begin{tabular}{|c|c|c|c|c|}
\hline Tube No. & Case & $\begin{array}{c}\text { Outer diameter } \\
(\mathbf{m m})\end{array}$ & $\begin{array}{c}\text { Wall Thickness } \\
(\mathbf{m m})\end{array}$ & $\begin{array}{c}\text { Pitch } \\
(\mathbf{m m})\end{array}$ \\
\hline 1 & Plain & 19 & 2 & - \\
\hline 2 & Fluted & 19 & 2 & 7 \\
\hline 3 & Fluted & 19 & 2 & 5 \\
\hline 4 & Fluted & 19 & 2 & 3 \\
\hline
\end{tabular}

Table 3 Falling film mode transitions correlations constants and RMS.

\begin{tabular}{|l|c|c|c|c|}
\hline & $\begin{array}{c}\text { Droplet / } \\
\text { Droplet-Jet }\end{array}$ & $\begin{array}{c}\text { Droplet-Jet / } \\
\text { Jet }\end{array}$ & $\begin{array}{c}\text { Jet / } \\
\text { Jet-Sheet }\end{array}$ & $\begin{array}{c}\text { Jet-Sheet / } \\
\text { Sheet }\end{array}$ \\
\hline $\mathrm{a}$ & 0.0785 & 0.0978 & 1.5031 & 1.491 \\
\hline $\mathrm{b}$ & 0.2965 & 0.2998 & 0.2273 & 0.2353 \\
\hline $\mathrm{RMS} \%$ & 7.95 & 5.2 & 4.8 & 3.3 \\
\hline
\end{tabular}

Table 4 Correlations constants of the transitions for different fluted tube.

\begin{tabular}{|c|c|c|c|c|c|}
\hline Tube & $\begin{array}{c}\text { Constants } \\
\& \text { RMS }\end{array}$ & $\begin{array}{c}\text { Droplet/ } \\
\text { Droplet-Jet }\end{array}$ & $\begin{array}{c}\text { Droplet-Jet } \\
\text { /Jet }\end{array}$ & $\begin{array}{c}\text { Jet / } \\
\text { Jet-Sheet }\end{array}$ & $\begin{array}{c}\text { Jet-Sheet / } \\
\text { Sheet }\end{array}$ \\
\hline \multirow{3}{*}{ Tube 2 } & $\mathrm{a}$ & 0.077 & 0.095 & 1.454 & 1.4953 \\
\cline { 2 - 6 } & $\mathrm{b}$ & 0.296 & 0.3 & 0.226 & 0.2322 \\
\cline { 2 - 6 } & $\mathrm{RMS} \%$ & 7.3 & 5.9 & 6.7 & 6.1 \\
\hline \multirow{3}{*}{ Tube 3 } & $\mathrm{a}$ & 0.077 & 0.093 & 1.4584 & 1.4577 \\
\cline { 2 - 6 } & $\mathrm{b}$ & 0.295 & 0.299 & 0.2226 & 0.23 \\
\cline { 2 - 6 } & $\mathrm{RMS} \%$ & 8.3 & 4.9 & 4.2 & 5.4 \\
\hline \multirow{3}{*}{ Tube 4 } & $\mathrm{a}$ & 0.076 & 0.092 & 1.4127 & 1.45 \\
\cline { 2 - 6 } & $\mathrm{b}$ & 0.294 & 0.298 & 0.2219 & 0.227 \\
\cline { 2 - 7 } & $\mathrm{RMS} \%$ & 6.7 & 7.9 & 6.3 & 9.1 \\
\hline
\end{tabular}

